\title{
nature
}

\section{How to slake a planet's thirst}

Our growing demand for water threatens the world's development and security. Solving this crisis need not involve flashy technologies. But it will require science, plus a large dose of political will.

B $y$ this time next year, some 1.75 million people will have died before their time for the simple reason that they must scratch out their existence without access to safe drinking water. This is the toll from cholera, dysentery and other diarrhoeal diseases that the World Health Organization attributes to unsafe drinking supplies.

United Nations (UN) officials had hoped that this week would hoist the injustice of these avoidable deaths to the top of the world's news agenda, through coverage of the 3rd World Water Forum. Now under way in Japan, the forum is billed as the most important meeting on freshwater resources ever held. But its organizers' plans for a high media profile have been undone by the crisis over Iraq all in all, this must be a depressing time to work for the UN.

Whatever transpires in the Iraqi desert over the next few weeks, the water crisis will still be with us, quietly exacting its devastating toll (see page 251). As the world's population continues to expand, and climate change alters the hydrology of river basins, as many as 7 billion people in 60 countries could face water scarcity by 2050 , if action isn't taken.

So what needs to be done? In large part, the answer lies in the development and large-scale application of relatively simple technologies. Sophisticated solutions such as solar-powered desalination plants have a role to play, particularly in wealthy yet arid countries, but the two biggest components of the global water crisis are the contamination of drinking supplies with human faeces, and the massive wastage of water that is inherent in prevailing agricultural practices. Both of these problems could be alleviated by refining and implementing existing technologies.

\section{Drain on resources}

The world's difficulties with sanitation might be eased if we abandon the idea of disposing of our waste with a flush. In the rich North, flush toilets are the largest single drain on domestic water supplies. But there is no need for the developing countries that currently lack adequate sanitation to imitate this wasteful practice, which would require substantial investment in sewage-treatment infrastructure. Ventilated, composting toilets can now safely turn human waste into an odourless, soil-like residue. Further development may be needed to reduce the cost of the technology. But as demands for water grow, this has to be a better solution than a system that involves the contamination and subsequent treatment of precious water supplies.

Meanwhile, irrigation for agriculture accounts for more than two-thirds of humanity's use of water. In many cases, the techniques used are much the same as when the farmers of Mesopotamia first diverted water from the Euphrates some 6,000 years ago: dig a channel from a river to your crops, and let gravity do the work. Thanks to seepage and evaporation, however, this can result in almost $60 \%$ of the diverted water being lost. Today, we do not need to be so wasteful. By using 'micro-irrigation', in which water is piped and fed onto crops through sealed systems, irrigation can be made $90 \%$ efficient. Much greater use could also be made of recycled waste water, rather than drawing from supplies that could be used for human consumption.
Getting bright young scientists and engineers interested in the world's water problems is vital. One difficulty, in that regard, is that composting toilets and micro-irrigation aren't seen as sexy topics. Yet there are prominent role models to show that scientific excellence and the application of appropriate technologies can go hand in hand. Step forward Rita Colwell, director of the US National Science Foundation, who for the past three decades has studied the factors that influence outbreaks of cholera. Today, her team's research incorporates the latest techniques of genomics and remote sensing, yet Colwell remains aware of the value of low-tech solutions. One of her most recent papers evaluates the use in Bangladesh of folded sari material to filter Vibrio cholerae, the cholera pathogen, from drinking water (R. R. Colwell et al. Proc. Natl Acad. Sci. USA 100, 1051-1055;2003).

\section{Political solution}

But it is at the political level that the battle to avert the global water crisis will ultimately be won or lost. For too long, politicians have tried to tackle problems with water resources through centralized control and grandiose engineering projects. 'If it flows, dam it', has been their mantra. These schemes have brought benefits through an expansion of hydroelectric power, and have allowed vast areas to be opened up for cultivation, but the human and environmental consequences have often been disastrous.

Take the Aral Sea, a giant salt lake between Kazakhstan and Uzbekistan in central Asia that is rapidly being turned into a dust bowl, destroying a unique ecosystem and with it the livelihoods and health of many of the region's 5 million people. This environmental catastrophe, today a source of tension between five nations, is a consequence of the former Soviet Union's policy of diverting water from the rivers that feed the Aral Sea to irrigate its vast plantations of cotton.

Such aberrations are not the exclusive preserve of socialist planning — witness Saudi Arabia's draining of its aquifers in the 1980s and 1990s in order to become an exporter of wheat, and the continuing obscenity of sprinklers watering golf courses in the parched western United States. We need to move away from such misguided adventures, which will require more decisions about water resources being taken in close consultation with local water users.

Most fundamentally, however, averting the global water crisis will require developed nations to summon the political will - and hard cash - to help the world's poorest countries tackle water-borne disease, and put their use of water on the path to sustainability. Officially, the world has already signed up to the goal of halving the number of people lacking access to safe drinking water by 2015. But this will cost tens of billions of dollars, and even before the crisis in Iraq consumed their attention, world leaders were showing little commitment to providing the necessary funds.

The 3rd World Water Forum is in danger of becoming "the biggest and most expensive non-event in history", one official with a UN agency confided to Nature last week. For the sake of the billionplus people for whom having a drink of water involves a game of microbiological Russian roulette, things have to change. 